\title{
DETECTION OF GENETICALLY MODIFIED ORGANISMS IN FOODS BY DNA AMPLIFICATION TECHNIQUES.
}

Virginia García-Cañas, Alejandro Cifuentes, Ramón González*

Institute of Industrial Fermentations, CSIC

Juan de la Cierva 3, 28006 Madrid, Spain

*Corresponding author:

rgonzalez@ifi.csic.es, Tel\# 34-91-5622900, Fax\# 34-91-5644853 


\section{TABLE OF CONTENTS}

Abstract

1. Introduction

2. Qualitative detection of GMOs in foods

2.1. Sampling plans

2.2. DNA isolation

2.3. DNA amplification

2.3.1. Target choice

2.3.1.1. Broad specificity detection

2.3.1.2. Specific detection

2.3.2. Dealing with false positives

2.3.2.1. Confirmation methods

\subsubsection{Carry-over control}

2.4. End-point detection of PCR products

3. Quantitative methods

3.1. Reference materials

3.2. QC-PCR

3.3. Real-Time PCR

4. Multiplex detection

5. Validation of methods

6. Conclusions

7. Acknowledgements

8. References 


\begin{abstract}
In this review, the different DNA amplification techniques that are being used for detecting genetically modified organisms (GMOs) in foods are examined. This work intends to provide an updated overview (including works published till June 2002) on the principal applications of such techniques together with their main advantages and drawbacks in GMO detection in foods. Some relevant facts on sampling, DNA isolation and DNA amplification methods are discussed. Moreover, these analytical protocols are discussed from a quantitative point of view including the newest investigations on multiplex detection of GMOs in foods and validation of methods.
\end{abstract}

KEY TERMS: transgenic, (transgenic) food, genetically modified organism (GMO), analysis of GMOs, novel ingredients 


\section{INTRODUCTION.}

Public attention to the use of genetic engineering in the production of foods is constantly growing since the past few years. This is due to the increasing impact of this technology in foodstuff production, by one side, and to the continued campaign against GMO crops leaded by ecologist organisations, by the other. Claims about advantages derived of GMO crops include those from biotechnology companies and most of the scientific community, stressing the benefits for the agriculture and the food industry and the lack of scientific evidence on any detrimental effects on human health. On the other side, ecologists' associations, are concerned about the impact of genetically modifiedGM plants on human health and on the environment. In this context, most governments have dictated regulations on the use, spreading and marketing of GMOs, in order to regain the confidence of the consumers.

In the European Union, Directive 2001/18/CE ${ }^{1}$ establishes the rules and limitations to the deliberate release into the environment of GMOs. It defines a GMO as "an organism, with the exception of human beings, in which the genetic material has been altered in a way that does not occur naturally by mating and/or natural recombination". Recombinant DNA technology is specifically under the scope of this Directive. Safety evaluation, marketing and labelling of foods or food ingredients consisting or containing GMOs, or that have been produced from them, is regulated by Regulation 258/97 ${ }^{2}$ on "Novel Foods and food ingredients". Regulations $1139 / 98^{3}, 49 / 2000^{4}$ and $50 / 2000^{5}$ (for food additives and aromas) complete the European legislation on labelling of food and food ingredients. The proposal 2001/0173 (COD) ${ }^{6}$ intends to harmonise criteria among these Regulations and Directives, including amendments for Regulation 
258/97 and the repealing of Regulations 1139/98, 49/2000 and 50/2000. In these Regulations it has been established, for approved GMOs, a 1\% content threshold for the requirement of labelling for feed, food, and food ingredients, provided that the presence of these GMOs is adventitious or technically unavoidable. In order to control the observance of the European Legislation regarding GMOs and taking into account the huge number of GM plant lines currently available for food an feed production, either approved or not, there is a need for detection methods capable to distinguish between approved and non-approved GMOs and quantify them.

Currently, all the GM crops officially assessed and approved world-wide have been obtained by recombinant DNA technology. This typically involves the insertion of a DNA fragment (insert) in the genome of an organism. The insert usually contains an expression cassette, consisting of control regions (promoter and terminator) and the gene coding for the desired character. The construction generally contains additional elements, mostly related to the transformation system used, e.g. antibiotic resistance or herbicide resistance when this is not the primary character, signalling peptides for fusion proteins, or introns..$^{7-10}$ In the case of transgenic plants, the GMO resulting from the stable insertion of a specific construction in the genome is known as a rmation event. It is characterised by the insertion, in a precise chromosomal location, of one or several copies, either complete or truncated, of the construct. In some instances, the insertion of the construct is associated with rearrangements of the plant genome. ${ }^{10}$

Genetic engineering is used in agriculture and food industries in order to improve the performance of plant varieties (resistance to plagues, herbicides, and hydric or saline stresses), improve technological properties during storage and processing (firmness of 
fruits), or improve the sensorial and nutritional properties of food products (starch quality, content on vitamins or essential amino acids). ${ }^{11-14}$

\section{QUALITATIVE DETECTION OF GMOs IN FOODS.}

Two types of macromolecules, specific for the genetic modification, have been used in order to reveal the presence of GMOs (or a derivative) in foods: proteins and DNA. Proteins specific for a given GMO are usually detected by ELISA tests (enzyme linked immunosorbent assay), based on the specific recognition of the protein by antibodies raised against the purified protein. This technique has proven to be useful for the analysis of raw materials. However, its performance is greatly affected by the expression levels of the transgen, which depend on the physiological state of the plant, and the specific tissue analysed. In addition, the integrity of the protein is readily affected by most food processing technologies. ${ }^{15-17}$ Some commercially available GMO-detection systems, also based on the use of antibodies, use lateral-flow strips. These systems are specially adapted for in-field applications but face similar problems than ELISA tests, and its validity has been questioned. ${ }^{18}$

In contrast to proteins, the higher thermal stability of DNA and the fact that it is present in most biological tissues makes it a more suitable analyte for GMO detection. Most DNA-based detection methods for GMOs rely on the use of polymerase chain reaction (PCR). ${ }^{19-21}$ One alternative to PCR-based detection methods is the use of DNA microarrays, in order to detect and quantify several GMOs in a single assay. However, very little information is still available on the reliability and quantification power of these methods. This review will focus on PCR-based GMO detection methods. 


\subsection{Sampling plans.}

The four main steps necessary for PCR analysis are: sample collection, DNA isolation, DNA amplification, and detection of the amplification products. The sampling strategy is perhaps the weakest step in the analysis of GMO content in foods, and is determinant for the quality of the results obtained. The objective of sampling is to be able to draw valid conclusions about the whole batch by performing the analysis of a limited amount of material, constituted by one or several representative samples. Because in the practice it is almost impossible to get 100 percent confidence that the sample truthfully reflects the composition of the batch, sampling strategies should be designed to achieve a reasonable compromise between the risk to accept a bad batch and that of rejecting one that is in compliance with GMO regulations. Due to its highest degree of heterogeneity, sampling plans carefully designed on the base of statistical considerations are especially important for the analysis of raw materials. The concern about representativity is much less pronounced in the case of food ingredients or processed food. Considerations to be observed in designing a sampling plan have been summarized in a recent review. ${ }^{22}$ These considerations are: the type of material (raw materials, derived ingredients or finished processed foods), the threshold limit for acceptance, cost of sampling and cost of analysis, the speed required to release the results, and the degree of risk acceptable from either side of the commercial transaction.

\subsection{DNA isolation.}

The integrity and purity of the DNA used are determinant for the efficiency of amplification, and hence for the ability to detect GMOs by PCR. Integrity of DNA is affected by several factors during food processing and DNA isolation (e.g., variations of 
$\mathrm{pH}$ and temperature, existence of nucleases). Chemical modifications, like depurination, and the mean size of the DNA molecules, influence the minimal size of the target sequences that can be amplified. Contaminants from the food matrix or from the chemicals used for DNA isolation can inhibit the PCR reactions. There is a high number of methods available for DNA extraction from biological samples but, in the case of transgenic plants, attention should be paid to the presence of polysaccharides in order to choice the best method. CTAB ${ }^{23}$ and affinity based methods ${ }^{24}$ are the most commonly

used, although phenol based methods have also proven to be useful ${ }^{25}$. Several alternatives should be tried when starting with a new food matrix in order to establish the most appropriate conditions.

\subsection{DNA amplification.}

There are some properties of DNA and DNA polymerases that are important to know in order to understand how PCR amplification works. First, the self-complementarity of the four nitrogenous bases found in deoxyribonucleotides is responsible for the fidelity of the replication process, so that, two double-stranded DNA molecules completely identical to the original one can be obtained (except for a low rate of errors). Complementarity is also responsible for the specificity of the interaction between single-stranded molecules, so that, under the appropriate conditions, only perfectly matching sequences will anneal (hybridise) to constitute a double-stranded molecule. Finally, DNA polymerases are able to catalyse the replication reaction (generating a complementary strand for a single-stranded molecule), but always from a pre-existing double-stranded stretch, and this only occurs in one direction. This double-stranded 
stretch is usually constituted by an oligonucleotide (primer) annealed to a singlestranded DNA molecule (template).

A PCR reaction is typically constituted by 20-40 repetitions of three consecutive temperature steps (cycles), consisting of separation of the strands of a double-stranded DNA (denaturation), anneal the primer to its target sequence (annealing), and synthesise the target's complementary strand (extension). The specificity of the amplification is achieved by using primers that perfectly match the ends of the target sequence. The primers should be chosen in complementary strands so that the target sequence of each one is in the path of the polymerase that initiates DNA from the other primer. The sensitivity of the amplification is due to the fact that the newly synthesised sequence can be used as template in the following cycle, so that, in ideal conditions, an exponential increase in the amount of target sequence can e expected. The availability of thermocyclers and thermostable polymerase, able to endure more than 40 thermal cycles, has made possible the automatisation of the whole process and the popularisation of this technology for both research and diagnostic applications.

\subsubsection{Target Choice.}

\subsubsection{Broad specificity detection methods.}

Screening methods, allowing for the detection of a relatively high number of different GMOs in foods, are essential tools for routine analysis. However, due to its broad specificity these methods do not allow for the unequivocal identification of discrete transformation events. The more common strategy pursues the amplification of 
sequences found in as many different GMOs as possible, e.g. some promoters and terminators used in most of the first GMOs approved for commercialisation. ${ }^{7}$ The two sequences more frequently used with this purpose are the promoter $P$-35S from Cauliflower mosaic virus (CaMV) and the nopaline synthase gene terminator, nos3', from Agrobacterium tumefaciens (see Table 1). Alternatively, some structural genes that are used very often in GMO crops in order to improve field performance or as part of the transformation system can also be the target for screening methods. This is the case of the synthetic gene cryIA(b) coding for endotoxin $\mathrm{Bt}$ from $B$. thuringiensis, which is used in several genetically modified corn varieties resistant to european corn borer, ${ }^{25-28}$ or the gene nptII, conferring resistance to neomycin. ${ }^{29}$ However, as new phenotypic characters, genetic markers, and transcription control regions, are being used in the production of transgenic plant varieties, this strategy is loosing interest. The utility of screening methods could be improved by the use of multiplex PCR reactions (see below). ${ }^{30}$

Another weakness of these screening methods is the possibility of obtaining false positive results due to contamination from non-GMO sources naturally containing the target sequences. This is the case of nos3' and P-35S, whose presence could be due to some strains of Agrobacterium tumefaciens or the Cauliflower mosaic virus respectively. $^{24,31}$

In spite of these limitations, detection methods based on sequences frequently found in GM plants are almost the only alternative to detect non-declared and non-characterised GMOs. This can be done, for example, by obtaining PCR fingerprints of the edge fragments by using a random primer in combination with a primer specific for the 
common element of choice ${ }^{32}$. This strategy has also been used for the characterisation of edge fragments, by chromosome walking, in order to develop specific detection methods (see below).

\subsubsection{Specific detection methods.}

Junction fragments, containing sequences of diverse origins in a particular arrangement, specific for a given transgenic construct, are better targets for the specific detection of GMOs. Usually these are promoter-structural gene, or structural gene-terminator junctions (Table 2), although the complexity of most of the constructions currently in use provides for additional specific junction fragments (Figure 1).

However, as a given construct can give rise to several transformation events, the best way to unequivocally detect a particular transgenic variety is by amplifying the edge fragments. These are unique for each transformation event and result from the combination of sequences in the transgenic construct and those at the insertion point at the genome of the host. ${ }^{10,32-34}$ It is interesting to remind that, under the EU Regulations, the subject of the authorisations for commercialisation is a specific transformation event, any other transgenic variety obtained with the same construct should go throughout all the authorisation process.

\subsubsection{Dealing with false positives.}

Due to the high sensitivity of the amplification reaction, PCR-based detection methods have to cope with the risk of false positive results. There are two main sources of false positive results in GMO detection: unspecific amplification of DNA fragments other 
than the intended GMO-specific target, and amplification of PCR products resulting from previous analyses (carry-over). Analysts handle these problems by using confirmation methods in the first case and by physical and enzymatic contention methods in the second one.

\subsubsection{Confirmation methods.}

The first obvious action in order to avoid false positives is to carefully optimise the PCR reaction, using appropriate positive and negative controls and taking full advantage of the ramp and gradient features of modern thermocyclers. However, as even a low risk of false positives should be avoided, especially for the analysis of large numbers of samples, additional confirmation methods have been developed in order to discriminate specific form unspecific amplicons. Depending on the features of each method they can be of help in the optimisation steps or both for optimisation and routine analyses. The simplest confirmation procedure is checking the size of the amplicon. Nevertheless, a coincidence in size is never taken as a definitive confirmation, because unspecific amplicons are sometimes indistinguishable from the specific one by ethidium bromide/agarose electrophoresis, which is commonly used for that purpose. The most reliable confirmation method is sequencing the amplicon but it is very expensive ${ }^{27}$ and its use is generally restricted to the optimisation steps. Usually, nested PCR is the method of choice, it consist in using the first amplicon as a template for a second PCR reaction that uses primers whose target sequence is in an internal position, relative to the first set of primers. Obtaining a DNA fragment of the expected size is taken a sufficient proof for the preliminary positive result. ${ }^{8,35-37}$ However, although nested PCR allows detecting primary false positives due to unspecific amplification, the increased sensitivity obtained by combining two PCR reactions in tandem implies an increased 
risk of false positives due to carry-over or to cross-contamination of the samples. Restriction analysis ${ }^{29,36,38-41}$ and Southern Blot $^{26,27,42,43}$ have also been used as confirmation methods.

\subsubsection{Carry-over control.}

False positives due to carry-over contamination cannot be discriminated by the confirmation methods described above, because the sequence of the amplicon obtained is identical for both true and false positives. The only way to fight carry-over in routine analysis is hence to adopt effective contention measures, by intensifying the precautions generally taken to avoid carry-over in research laboratories (separate rooms for sample preparation and analysis, specific material for each step of the analytical procedure, and laminar flow cabins to avoid air-driven contamination). In addition to these physical contention measures, Longo et al. ${ }^{44}$ developed a tool against carry-over consisting in the combined use of dUTP (instead of dTTP) for the amplification reactions, and UracilDNA glycosylase (UDG). Reaction mixtures containing UDG are incubated at $37^{\circ} \mathrm{C}$ in order to allow the enzyme to remove uracil from DNA coming from any previous amplification, so that it cannot be longer amplified. The enzyme is heat inactivated during the first long denaturation step preceding thermal cycling. This system has been included in some commercially available kits.

\subsection{End-point detection of PCR products.}

The final stage of PCR-based analysis (except for Real-Time PCR, that will be discussed below), consists in the separation and detection of the PCR products. The most popular technique for that purpose is agarose electrophoresis, combined with 
ethidium bromide staining. The main advantages of this technology are the simplicity and cost effectiveness, and the fact that it is implemented in almost every Molecular Biology laboratory worldwide. Nevertheless, the limited sensitivity and resolution, and the difficulties to get quantitative results and for automation, have forced the development of alternatives, either for the detection itself of both for separation and detection. Examples of alternative detection methods are the use of CCD cameras instead of photography, ${ }^{32,45}$ or the use of isotopic labelling of the PCR products, followed by electrophoresis and detection by autoradiography or scintillation counting of gel slices. ${ }^{46,47}$

Independently of the detection method employed, one major drawback of methods based in agarose or acrylamide gel electrophoresis is that two steps are necessary in order to perform the analysis, which extends the analysis time and hinders the accuracy and precision of the results. One-step procedures based on HPLC or capillary electrophoresis constitute an interesting alternative. One example is ion-pair reversedphase HPLC using alkylated polystyrene-divinylbenzene packing and on-line UV absorbance detection. ${ }^{48-50}$ Capillary electrophoresis applied to GMO detection has the advantages of a high degree of automation; with on-line detection systems, minimal requirement of sample and reagents, and very efficient PCR product separations. ${ }^{51,52}$ Most of these alternative detection methods could be especially useful in combination with the QC-PCR methods described below. 


\section{QUANTITATIVE METHODS.}

Its high sensitivity has made PCR the technique of choice in order to qualitatively detect the presence of GMOs in foods. However, inherent features of the PCR together with differences in the composition of the samples, constrain its use for accurate quantification of GMOs in food samples. This is due to the fact that amplification efficiency is never $100 \%$, so that the theoretical equation that would describe the relationship between the initial and the final number of copies of the target sequence: $\mathrm{N}=\mathrm{N}_{0} \cdot(2)^{\mathrm{n}}$, becomes $\mathrm{N}=\mathrm{N}_{0} \cdot(1+\mathrm{E})^{\mathrm{n}}$, where $\mathrm{N}_{0}$ and $\mathrm{N}$ are, respectively, the initial and final number of copies, $\mathrm{n}$ is the number of cycles and $\mathrm{E}$ is the actual amplification efficiency. The $\mathrm{E}$ value is affected by sample composition (presence of inhibitors), the sequences of the primers and target DNA, and the number of cycles. The effect of the number of cycles on the E value is specially relevant and is the responsible of most PCR reactions reaching a "plateau" phase (no neat increase in the product recovered after each additional cycle), due to progressive inactivation of the DNA polymerase, the exhaustion of reactives and the increasing competition, during the annealing step, between the primers and the newly synthesised DNA molecules. ${ }^{53}$ As a consequence, it is not possible to establish a direct relationship between the final quantity of PCR product and the initial concentration of the target in the sample. Quantitative PCR methods have been developed in order to solve these problems and, as a consequence,

the limited reproducibility of standard PCR methods between laboratories. ${ }^{54}$ Two main strategies are currently in use for quantitative detection of GMOs in foods: quantitative competitive PCR (QC-PCR) and Real-Time PCR. 


\subsection{Reference materials.}

One critical step of any quantitative analytical procedure is the calibration of the system, which is performed by using reference materials in which the amount of the analyte of interest is known. Whenever possible, the use of reference materials certified by a recognised institution is advisable (for example the IRMM). However, the availability of certified standards is limited to Roundup Ready ${ }^{\mathrm{TM}}$ soya and MON810 maize. This lefts the vast majority of GMOs either approved outside the CE or not approved, orphan of certified reference materials. The utility of certified reference materials (CRMs) is also compromised by the fact that they are prepared from unprocessed raw materials. Quantification based in the direct comparison of results obtained from processed samples and those from CRMs should be taken with care, because matrix effects and the loss of integrity of the DNA molecules during processing could lead to underestimation of the actual GMO content of the samples.

\subsection{QC-PCR.}

In QC-PCR quantification is performed by comparing the signal corresponding to the target sequence with that of a competitor, in a series of reactions in which one of them is maintained constant while the other is changed. Competitors are DNA molecules of known concentration that are added to the reaction mixture and compete with the target DNA for the same pair of primers. ${ }^{55}$ The base of quantification is the determination of the equivalence point. By plotting $\log \left(\mathrm{X}_{\mathrm{n}} / \mathrm{C}_{\mathrm{n}}\right)$ versus $\log \mathrm{C}_{0}$ (being $\mathrm{X}_{\mathrm{n}}$ the molar quantity of target product, $\mathrm{C}_{\mathrm{n}}$ that of competitor, obtained after $\mathrm{n}$ amplification cycles, and $\mathrm{C}_{0}$ the different initial quantities of competitor added to the reaction mixture) a equivalence 
point should be found in which the same quantity of product is obtained for the original target and for the competitor: $\log \left(\mathrm{X}_{\mathrm{j}} / \mathrm{C}_{\mathrm{j}}\right)=0$. Whenever the respective amplification efficiencies for the target and the competitor $\left(E_{x} y E_{c}\right)$ are identical a straight line with slope -1 that fits equation 1 should be obtained. In that case, it is possible to calculate the initial quantity of target sequence from that of competitor $\left(\mathrm{C}_{0}\right)$ at the "equivalence point".

$$
\log \left(\frac{X_{n}}{C_{n}}\right)=\log X_{0}-\log C_{0}+n \cdot \log \left[\frac{\left(1+E_{X}\right)}{\left(1+E_{c}\right)}\right]
$$

Quantification of GMOs by QC-PCR is usually completed in two steps. ${ }^{45}$ First, the amount of competitor is adjusted to reach the equivalence point at 1\% GMO content. It is convenient to verify the linearity of the calibration curve in the range of GMO content desired, by constructing other calibration curves with multiples of the previously adjusted amount of competitor. For quantification, DNA extracted from unknown samples is co-amplified with varying amounts of the previously calibrated competitor in order to find the equivalence point (Figure 2).

A good quantification can only be obtained when the target and the competitor sequences are amplified with the same efficiency throughout the reaction time. This makes the design of the competitor DNA crucial for the development of any QC-PCR method. There are two additional conditions that a competitor must fulfil, it should be amplified with the same primer pair than the target sequence, and it should contain some differential property in order to be distinguished from the original target. Usually, competitor DNA fragments are constructed by recombinant DNA technology, using the 
cloned target sequence as a background in order to introduce "in vitro" small insertions, deletions or single nucleotide changes that will modify the size or the restriction pattern in relation to the original target sequence. Care should be taken when manipulating the size of the competitors because it could greatly influence the amplification efficiency. ${ }^{56}$, 57 Multispecific competitors, containing targets for several pairs of primers, corresponding to several GMOs, have also been designed, ${ }^{58,59}$ but this technique should face the problem of the different amplification efficiencies of the target sequences with that of the common competitor.

The quality of the results of any QC-PCR analysis is also influenced by the technology used in order to detect and quantify the amplification products. For example, most reports still use conventional agarose electrophoresis and ethidium bromide staining. This sometimes leads to plots of $\log \left(\mathrm{X}_{\mathrm{n}} / \mathrm{C}_{\mathrm{n}}\right)$ vs. $\log \mathrm{X}_{0}$ that do not display a slope equal to -1 . This discrepancy of the slope of the pattern has been attributed to the lack of uniformity of the gel and the insufficient signal/noise ratio. ${ }^{59}$ The application of onestep, more quantitative methods will probably help to solve these problems in the near future. $^{48-52}$ The application of laser induced fluorescence detection systems (LIF) coupled to capillary gel electrophoresis (CGE) has provided extremely low detection limits, ${ }^{25,60}$ and offers an interesting alternative to gain precision and sensitivity in the quantification of PCR products from competitive and multiplex PCR reactions. ${ }^{61-63}$ Additionally, the CDCE technique (Constant-Denaturant Capillary Electrophoresis) allows to minimise the size differences among the specific and competitor sequences because it admits the employment of competitors very similar to the specific sequence without necessity of restriction analysis. ${ }^{64}$ 
There are several reports on the use of QC-PCR for quantification of transgenic soya or maize in food. In these procedures, PCR products are analysed by conventional agarose gel electrophoresis, ethidium bromide staining and visual estimation of the equivalence point $^{65}$ or computer analysis of a digital image obtained with a CCD camera. ${ }^{32,45}$ Certified reference materials are commonly used for calibration of these systems, but, as mentioned above, this could lead to underestimation of specific transgenic varieties in processed food. ${ }^{66}$ In order to overcome this problem, quantification results for a transgenic sequence are referred to the quantity of a control target sequence, preferentially of a similar size, that should be present in equal amounts in the transgenic and the conventional varieties. ${ }^{67}$ This is sometimes referred to as double competitive quantitative PCR (DC-PCR). Genomic heterogeneity among different commercial plant cultivars makes often difficult the choice for such internal standards.

One drawback of QC-PCR is that the use of a double logarithmic scale can lead to miss small differences in the percentage of transgenic varieties. ${ }^{68}$ Compared to Real-Time PCR (vide infra), the development of analysis procedures by QC-PCR is more timeconsuming (UE Tender Report No. XXIV/98/A3/001) and less automatic, even though the later is being solved by recent developments. ${ }^{69,58}$ The results from several European collaborative studies have shown that the use of QC-PCR for GMO detection in foods leads to an improvement in the results as compared to standard PCR. The remaining variability in the results could be attributed to deficient homogenisation of the samples or to inaccurate quantification of the amplification products. ${ }^{70}$ However, most of these problems could probably be overcome by the use of appropriate internal controls. 


\subsection{Real-Time PCR.}

The main singularity of Real-Time PCR is that the amount of amplicon formed can be monitored and quantified after each amplification cycle. This is achieved by the use of fluorescent markers than can be double-stranded DNA binding dyes (intercalating agents) or complex sequence-specific probes. The main parameters used to quantify the target sequence by Real-Time PCR are the threshold fluorescence signal, set as a given value statistically significant above the noise, and the threshold cycle $\left(\mathrm{C}_{t}\right)$, defined as the cycle number at which the fluorescence surpasses the threshold. ${ }^{71}$ In order to make the results reproducible, the threshold value is chosen in the exponential phase of the amplification. Under ideal conditions, $\mathrm{C}_{\mathrm{t}}$ number is inversely proportional to the amount of target sequence at the beginning of the reaction. This allows the generation of standard curves on which the $C_{t}$ number obtained from problem samples is plotted.

The simplest way to perform Real-Time PCR analysis is by using intercalating agents. In their pioneering work, Higuchi et al., ${ }^{72}$ used ethidium bromide, and currently YOPRO-1 and SYBR Green I are used. ${ }^{73}$ These assays have a sensitivity below 10 copies of the target sequence and a variation coefficient higher than $34 \%$ with SYBR Green I. ${ }^{74}$ One difficulty encountered by using intercalating agents is that it is very difficult to check for the specificity of the amplification, so increasing the risk of false positive assignment. The confirmation methods used for PCR reactions with end-point detection cannot be used in Real-Time PCR. Instead, specific confirmation methods have been developed. 
Two confirmation methods have been proposed for amplification reactions incorporating intercalating agents, but they are not completely reliable. One is based on the amount of DNA in the "plateau" phase, which should be proportional to the size of the amplicon. ${ }^{72}$ In addition, some commercial systems incorporate the possibility to obtain thermal denaturation curves as a mean to confirm the identity of the amplicon. ${ }^{73}$, ${ }^{74}$ None of the above-mentioned systems is compatible with multiplex assays.

The most reliable results for quantification using Real-Time PCR are obtained by simultaneously performing the detection and confirmation of the new products generated after each new PCR cycle, using probes or primers labelled with fluorescent dyes. The interaction of the probe with the DNA, in a specific moment of the PCR cycle, induces an increase of the quantum yield. ${ }^{75}$ The most common form is an oligonucleotide that contains both a fluorophore that emits fluorescence when excited, and a quencher that shields this emission when it is close to the fluorophore (up to 10100 Á). As a consequence of, either the 5'-3' exonuclease activity of the DNA polymerase (TAQMAN probes) or specific interactions between the amplicon and the probe (SCORPION primers and Molecular Beacons), ${ }^{76-78}$ a physical separation between fluorophore and quencher takes place, and therefore and increase in the fluorescence intensity is detected. This allows for the quantification of either the product formed in the last cycle or the product accumulated throughout all the previous cycles ${ }^{79-80}$ (Figure 3). Other alternatives include the use of two probes carrying fluorophores whose excitation and emission wavelengths are in resonance (FRET technology), the use of light-up probe consisting of a peptide nucleic acid-thiazole orange conjugate to improve hybridization and insensitivity to changes in salt concentration properties, ${ }^{81}$ or simply the use of primer conformation changes due to hybridization with its target sequence. ${ }^{82}$ 
The main advantages of Real-Time PCR are: minimal risk of cross-contamination, due to the use of a single tube for both amplification and detection, high processing capability, and short analysis times. ${ }^{75}$ The availability of an increasing number of PCR machines including computer-driven fluorescence analysis is contributing to the popularity of this technology. However, both the specialised equipment needed, and the cost of the probes, make it still a very expensive technology. In addition, the problems encountered for the development of multiplex assays have not been completely resolved so far, mostly due to spectral overlap when several fluorophores are included in the same reaction.

Similar to QC-PCR, Real-Time PCR applied to the detection of GMOs makes use of species-specific sequences as internal standards. ${ }^{83}$ In this way, the relative concentration of a given GMO is referred to the amount of amplifiable DNA from the cognate plant species, and is expressed as GMO percentage in weight. ${ }^{67,84}$ The results for this quantification are more reliable when both the transgen-specific and the species-specific sequences are amplified in the same reaction, and this implies the use of different fluorochromes for the quantification of each amplicon. Some examples on the use of this technology, applied to the quantification of GMOs in food samples, are maize: Bt176 and Mon 810, soya: Roundup Ready and several rapeseed transgenic lines. ${ }^{85-88}$ Among the available detection technologies FRET, ${ }^{34}$ TaqMan probes ${ }^{33,85,89,90}$ and Scorpion primers have been used. ${ }^{86}$ A comparative study showed that for the quantification of Roundup Ready soya, TaqMan proves are more sensible (20 copies) and exact than Scorpion primers. ${ }^{86}$ 


\section{MULTIPLEX ASSAYS.}

One of the biggest challenges for GMO control in foods is the ever-increasing number of genetically modified crops, microorganisms, and probably in near future, animals, that are being made available for the agro-food industries. By september 2002 there were already more than 100 transformation events, corresponding to around 60 different constructions and 15 species, ${ }^{91}$ approved world-wide for food and/or feed applications, and this is just the tip of the iceberg. In order to address this challenge, several laboratories are developing multiplex assays, allowing for the simultaneous detection and quantification of several GMOs. A multiplex assay consists in the simultaneous amplification of several target sequences in a single PCR reaction. Although the concept is simple, the different optimal conditions required to obtain each amplicon make it difficult to find the amplification conditions that allow for an acceptable yield of all the targets without generating unspecific amplifications. Henegariu et al., ${ }^{92}$ have proposed an step-by-step optimisation procedure for multiplex PCR reactions taking into account extension temperature and time, annealing temperature, dNTP/magnesium chloride ratio, salt concentration, and primer concentration. In addition, Kapley et al., ${ }^{93}$ have shown the importance of the cycling parameters, and specifically of the gradients between temperature steps for multiplex PCR optimisation. Shuber et al. ${ }^{94}$ have designed an alternative strategy for rapid optimisation of multiplex assays of up to 15 target sequences. The system uses specific primers with a common 5' extension, in combination with a shorter primer consisting in only this 5' extension. Multiplex ligation-dependent probe amplification (MLPA) constitutes one of the latest advances in multiplex quantitative detection of specific sequences. It was developed for the quantification of gene dosage in human samples ${ }^{95}$, but the authors anticipate further 
developments for the relative quantification of mRNAs. It is foreseeable that such developments will also be useful for the relative quantification of GMOs in food samples.

Capillary gel electrophoresis is a promising tool in this field for both the analysis and optimisation of multiplex assays. ${ }^{95,96,97}$ The different amplicons in a multiplex assay can be distinguished by capillary gel electrophoresis based in size by using intercalating agents, which makes the costs of the multiplex analyses lower than Real-Time PCR. The most recent developments in multiplex assays, using a high number of similarly sized amplicons would not have been possible without the use of capillary electrophoresis. $^{95}$

One example of the application of multiplex PCR to GMO detection has been published by Matsuoka et al., ${ }^{30}$ who were able to identify, in a single amplification reaction, up to 5 different maize varieties approved for commercialisation in Japan. The method uses 6 pairs of primers, one for the internal control and the other for the five transgenes, with a detection limit of $0.1 \%$ for each maize variety.

\section{VALIDATION OF METHODS.}

In order to control the compliance of product labelling with regulations concerning GMOs in food, it is necessary to make available methods officially validated. The aim of a validation process is to show that the combination of steps necessary to perform a GMO detection, including DNA extraction, amplification, and the analysis of the amplification products, gives precise, reproducible and accurate results for a given 
procedure and a given food matrix. ${ }^{98}$ The parameters used for validation are different for qualitative or quantitative methods. Validation of an analytical qualitative method involves the study of the specificity, sensitivity, precision and robustness, while for quantitative methods limit of quantification and linearity range are also accounted for. ${ }^{98}$

Very few of the PCR-based detection methods published so far, either qualitative of quantitative, have passed through a validation process including inter-laboratories ringtrials. The results for two collaborative studies for qualitative GMO-detection methods have been published. Perhaps one of the most thoroughly validated methods is the screening method for transgenic maize in processed food matrixes described by Lipp et al. ${ }^{41}$ In that study, ${ }^{41} 14$ out of 23 laboratories sent 100 percent correct results and three of them gave less than $20 \%$ of false positives. The remaining six laboratories were discarded, mainly because the high number of false positives suggested internal contamination (probably carry-over). A Swiss study detected at least ten-fold differences in sensitivity between laboratories for GMO detection. ${ }^{65}$ It has been suggested that the use of quantitative methods would help to improve the reproducibility between laboratories. ${ }^{65,99}$

Several validation studies of quantitative PCR methods have been reported during the last few years, either by QC-PCR ${ }^{99}$ or by Real-Time PCR. In a validation study of a double QC-PCR method for event 176 maize and Roundup Ready soy with visual estimation of the equivalence points, some laboratories indicated that interpretation was sometimes difficult, especially when the band intensities of two different competitor mix dilutions were similar. The main conclusions of this report are that more reliable detection methods should be used for QC-PCR, and that including a qualitative 
detection step previous to the DC-PCR analysis can help to reduce the number of false positives. $^{100}$

\section{CONCLUSIONS.}

In the last ten years, classical PCR procedures have demonstrated their usefulness to qualitatively detect genetically modified organisms in foods. However, the apparition in the market of new foods and food products containing GMOs has created the need for new analytical methods allowing for a qualitative and, mainly, quantitative analysis of these GMOs. Currently, there are several combinations of amplification, detection and quantification technologies available for GMO detection, but very few of them have passed through a validation process in order to be confidently used by enforcement and commercial laboratories. In order to provide the control organisms with the appropriate tools, and given the path of the evolution of the GMO market, future research in this field should focus on methods able to reliably detect and quantify several different GMOs in a single analysis.

In addition, reference materials appropriate for a range of food matrixes and covering both approved and non-approved GMOs, and a deeper effort on the validation of detection and quantification methods are absolutely necessary in order to make all the previous and future efforts in the development of GMO-detection and quantification methods useful for the public in general. 


\section{ACKNOLEDGEMENTS.}

VGC thanks to Consejería de Educación y Cultura (Comunidad de Madrid) for a fellowship. Work in the laboratory of RG is supported by grant AGL2000-1569 from the Spanish Ministerio de Ciencia y Tecnología. 


\section{REFERENCES}

(1) Council Directive 2001/18/EEC of 12 Mar 2001 on the deliberate release into the environment of genetically modified organisms and repealing Council Directive 90/220/EEC, OJ No L106/1, 17.4.2001.

(2) Regulation (EC) No 258/97 of the European Parliament and of the Council of 27 January 1997 concerning novel foods and novel food ingredients, OJ No L043, 14.2.1997, pp 1-7.

(3) Council Regulation (EC) No 1139/98 of 26 May 1998 concerning the compulsory indication of the labelling of certain foodstuffs produced from genetically modified organisms of particulars other than those provided for in Directive 79/112/EEC, OJ no L159, 3.6.1998, pp 4-7.

(4) Commission Regulation (EC) No 49/2000 of 10 Jan 2000 amending Council Regulation (EC) No 1139/98 concerning the compulsory indication of the labelling of certain foodstuffs produced from genetically modified organisms of particulars other than those provided for in Directive 79/112/EEC, OJ No L006, 11.1.2000, pp 13-14.

(5) Commission Regulation (EC) No 50/2000 of 10 Jan 2000 on the labelling of foodstuffs and food ingredients containing additives and flavourings that have been genetically modified or have been produced from genetically modified organisms, OJ No L006, 11.1.2000, pp 15-17. 
(6) Proposal 2001/0173 for a Regulation of the European Parliament and on the Council on genetically modified food and feed. http://europa.eu.int/comm/food/fs/ gmo/biotech08_en.pdf

(7) MacCormick, C.A., Griffin, H.G., Underwood, H.M., Gasson, J.M., Common DNA sequences with potential for detection of genetically manipulated organisms in food, J. Appl. Microbiol., 1998; 84:969-980.

(8) Zimmermann, A., Lüthy, J., Pauli, U., A sensitive detection method for genetically modified MaisGard ${ }^{\mathrm{TM}}$ corn using a nested PCR-system, Z Lebensm. Unters Forsch A, 1998; 207:81-90.

(9) Jankiewicz, A., Broll, H., Zagon, J., The official method for the detection of genetically modified soybeans (German Food Act LMBG 35): a semi-quantitative study of sensitivity limits with glyphosate-tolerant soybeans (Roundup Ready) and insect-resistant Bt maize (Maximizer), Eur. Food Res. Technol., 1999; 209:77-82.

(10) Windels, P., Taverniers, I., Depicker, A., Van Bockstaele, E., De Loose, M., Characterisation of the Roundup Ready soybean insert, Eur. Food Res. Technol., 2001; 213:107-112.

(11) Koziel, M.G., Beland, G.L., Bowman, C., Carozzi, N.B., Crenshaw, R., Crossland, L., Dawson, J., Desai, N., Hill, M., Kadwll, S., Launis, K., Lewis, K., Maddox, D., McPherson, K., Meghji, M.R., Merlin, E., Rhodes, R., Warren, GG.W., Wright, 
M., Evola, S.V., Field performance of elite transgenic maize plants expressing an insecticidal protein derived from Bacillus thuringiensis, BioTechnology, 1993; 11:194-200.

(12) Gao, A.G., Hakimi, S.M., Mittanck, C.A., Wu, Y., Woerner, H., Stark, D.H., Shah, D.H., Liang, J., Tommens, C.M., Fungal pathogen protection in potato by expression of a plant defensin pepetide, Nature Biotech., 2000; 18:1307-1310.

(13) Gisbert, C., Rus, A.M., Bolarín M.C., López-Coronado, J.M., Arrillaga, I., Montesinos, C., Caro, M., Serrano, R., Moreno, V., The yeast HAL1 gene improves salt tolerance of transgenic tomato, Plant Physiol., 2000; 123:393-402.

(14) Schwall, G.P., Safford, R., Westcott, R.J., Jeffcoat, R., Tayal, A., Shi, Y.C., Gidley, M.J., Jobling, S.A., Production of very-high-amylose potato starch by inhibition of SBE A and B, Nature Biotechnol., 2000; 18:551-554.

(15) An, H., Wei, S.I., Zhao, J., Marshall, M.R., Lee, C.M., Electrophoretic identification of fish species used in surimi products, J. Food Sci., 1989; 54:253257.

(16) Allmann, M., Candrian, U., Höfelein, C., Lüthy, J., Polymerase chain reaction (PCR): a possible alternative to immunochemical methods assuring safety and quality of food, Z. Lebensm. Unters. Forsch., 1999; 196:248-251. 
(17) Lüthy, J., Detection strategies for food authenticity and genetically modified foods, Food Control, 1999; 10:359-361.

(18) Fagan, J., Schoel, B., Haegert, A., Moore, J., Beeby, J., Performance assessment under field conditions of a rapid immunological test for transgenic soybeans, Int. J. of Food Sci. Technol., 2001; 34:357-367.

(19) Saiki, R.K., Scharf, S., Faloona, F., Mullis, K.B., Horn, G.T., Erlich, H.A., Arnheim, N., Enzymatic amplification of beta-globin genomic sequences and restriction site analysis for diagnosis of sickle cell anemia, Science, 1985; 230:1350-1354.

(20) Mullis, K., Fallona, F.A., Specific synthesis of DNA in vitro via PolymeraseCatalyzed Chain Reaction, Methods in enzymology, 1987;155:335-350.

(21) Saiki, R.K., Gelfand, D.H., Stoffel, S., Stephen, J.S., Higuchi, R., Horn, G.T., Mullis, K.B., Erlich, H.A., Primer-directed enzymatic amplificaction of DNA with a thermostable DNA polymerase, Science, 1988; 239:487-491.

(22) Gilbert, J., Sampling of raw materials and processed foods for the presence of GMOs, Food Control, 1999; 10:363-365.

(23) Murray, M.G., Thompson, W.F., Rapid isolation of high molecular weight plant DNA, Nucleic Acids Research, 1980; 8:4321-4325. 
(24) Meyer, R., Development and application of DNA analytical methods for the detection of GMOs in food, Food Control, 1999; 10: 391-399.

(25) García-Cañas, V., González, R., Cifuentes, A., Detection of genetically modified maize by the Polymerase Chain Reaction and Capillary Gel Electrophoresis with UV detection and Laser-Induced Fluorescence, J. Agric. Food Chem., 2002; 50:1016-1021.

(26) Studer, E., Dahinden, I., Lüthy, J., Hübner, P., Detection of the genetically engineered Maximizer Maize using the polymerase chain reaction (PCR), Mitt. Gebiete Lebensm. Hyg., 1997; 88:515-524.

(27) Hupfer, C., Hotzel, H., Sachse, K., Engel, K.H., Detection of genetically modified insect-resistant $\mathrm{Bt}$ maize by means of polymerase chain reaction, Z. Lebensm. Unters. Forsch. A, 1997, 205:442-445.

(28) Hurst C.D., Knight, A., Bruce I.J., PCR detection of genetically modified soya and maize in foodstuffs, Mol. Breeding, 1999, 5:579-586.

(29) Pietsch, K., Waiblinger, H.U., Brodmann, P.,Wurz, A., Screeningverfahren zur Identifizierung “genetechnisch veränderter” pflanzlicher Lebensmittel, Dtsch. Lebensm. Rundsch., 1997; 93:35-38.

(30) Matsuoka, T., Kuribara, H., Akiyama, H., Miura, H., Goda, Y., Kusakabe, Y., Isshiki, K., Toyoda, M., Hino, A., A multiplex PCR method of detecting 
recombinant DNAs from five lines of genetically modified maize, J. Food Hyg. Soc. Japan, 2001; 42:24-31.

(31) Wolf, C., Scherzinger, M., Wurz, A., Pauli, U., Hübner, P., Lüthy, J., Detection of cauliflower mosaic virus by the polymerase chain reaction: testing of food components for false-positive 35S-promoter screening results, Eur. Food Res. Technol., 2000; 210:367-372.

(32) Zimmermann, A., Lüthy, J., Pauli, U., Event specific transgene detection in Bt11 corn by quantitative PCR at the integration site, Lebensm. Wiss u. Technol., 2000; 33:210-216.

(33) Berdal, K.G., Holst-Hensen, A., Roundup Ready soybean event-specific real-time quantitative PCR assay and estimation of the practical detection and quantification limits in GMO analyses, Eur. Food Res. Technol., 2001; 213:432-438.

(34) Taverniers, I., Windels, P., Van Bockstaele, E., De Loose, M., Use of cloned DNA fragments for event-specific quantification of genetically modified organisms in pure and mixed food products, Eur. Food Res. Technol., 2001; 213:417-424.

(35) Köppel, E., Stadler, M., Lüthy, J., Hübner, P., Sensitive Nachweismethode für die gentechnisch veränderte sojabohne Roundup Ready ${ }^{\mathrm{TM}}$, Mitt. Gebiete Lebensm. Hyg., 1997; 88:164-175. 
(36) Hassan-Hauser, C, Mayer, W., Hörtner, H., Detection of the starch modifying gbss-antisense construct in transgenic potatoes, Z. Lebensm. Unters. Forsch. A., 1998; 206:83-87.

(37) Van Duijin, G., Van biert, R., Bleeker-Marcelis, H., Peppelman, H., Hessing, M., Detection methods for genetically modified crops, Food Control, 1999; 10:375378.

(38) Meyer, R., Nachweis gentechnologisch veränderte Pflanzen mittels der Polymerase Kttenreaktion (PCR) am beispiel der FLAVR SAVR ${ }^{\mathrm{TM}}$-Tomate, $Z$. Lebensm. Unters. Forsch., 1995; 201:583-586.

(39) Brodmann, P., Eugster, A., Hübner P., Meyer, R., Pauli, U., Vögeli, U., Lüthy, J., Detection of the genetically engineered Roundup ReadyTM soybeans using the Polymerase Chain Reaction (PCR), Mitt. Gebiete Lebensm. Hyg., 1997; 88:722731.

(40) Lipp, M., Brodmann, P., Pietsch, K., Pauwels, J., Anklam, E., et al., IUPAC Collaborative trial study of a method to detect genetically modified soy beans and maize in dried powder, J. AOAC Int., 1999; 82:923-928.

(41) Lipp, M., Bluth, A., Eyquem, F., Kruse, L., Schimmel, H., Van den Eede, G., Anklam, E., Validation of a method based on polymerase chain reaction for the detection of genetically modified organisms in various processed foodstuffs, Eur. Food Res. Technol., 2001; 212:497-504. 
(42) Vollenhofer, S., Burg, K., Schmidt, J., Kroath, H., Genetically modified organisms in food - Screening and specific detection by polymerase chain reaction, J. Agric. Food Chem., 1999; 47:5038-5043.

(43) Hupfer, C., Hotzel, H., Sachse, K., Engel, K.H., Detection of the genetic modification in heat-treated products of Bt maize by polymerase chain reaction, $Z$. Lebensm. Unters. Forsch. A, 1998; 206:203-207.

(44) Longo, M.C., Berninger, M.S., Hartley, J.L., Use of uracil DNA glycosylase to control carry-over contamination in polymerase chain reactions, Gene, 1990; 93:125-128.

(45) Studer, E., Rhyner, C., Lüthy, J., Hübner, P., Quantitative competitive PCR for the detection of genetically modified soybean and maize, Z. Lebensm. Unters. Forsch. A, 1998; 207:207-213.

(46) Souazé, F., Ntodou-Thomé, A., Tran, C.Y., Rostène, W., Forgez, P., Quantitative RT-PCR: Limits and Accuracy, BioTechniques, 1996; 21:280-285.

(47) Dostal, D.E.; Rthblum, K.N; Baker, K.M., An improved method for absolute quantification of mRNA using multiplex polymerase chain reaction: determination of renin and angiotensinogen mRNA levels in various tissues, Anal. Biochem., 1994; 223:239-250. 
(48) De Kant, E., Rochlitz, C.F., Herrmann, R., Gene expression analysis by competitive and differential PCR with antisense competitors, BioTechniques, 1994; 17:934-942.

(49) Hayward-Lester, A., Oefner, P.J., Sabatini, S., Doris, P.A., Accurate and absolute quantitative measurement of gene expression by single-tube RT-PCR and HPLC, Genome Research, 1995; 5:494-499.

(50) Hayward-Lester, A., Oefner, P.J., Doris, P.A., Rapid quantification of gene expression by competitive RT-PCR and Ion-Pair Reversed-Phase HPLC, BioTechniques, 1996; 20:250-257.

(51) García-Cañas, V., González, R., Cifuentes, A., Highly reproducible Capillary Gel Electrophoresis (CGE) of DNA fragments using uncoated columns. Detection of genetically modified maize by PCR-CGE, J. Sep. Sci., 2002; 25:577-583.

(52) García-Cañas, V., González, R., Cifuentes, A., Detection of genetically modified maize by PCR and Capillary Gel Electrophoresis (CGE) using uncoated columns, In: Annals of the MCFA Volumen II, Brussels: European Commission, 2002, (in press).

(53) Zhang, J., Day, I.N., Byrne, C.D., A novel medium throughput quantitative competitive PCR technology to simultaneously measure mRNA levels from multiple genes». Nucleic Acids Research, 2002; 30, No. 5 e20 (10 pp.). 
(54) Hübner, P., Studer, E., Lüthy, J., Quantitative competitive PCR for the detection of genetically modified organisms in food, Food Control, 1999; 10:353-358.

(55) Piatak, M., Saag, M.S., Yang, L.C., Clark, S.J., Kappes, J.C., Luk, K.C., Hahn, B.H., Shaw, G.M., Lifson, J.D., High levels of HIV-1 in plasma during all stages of infection determined by competitive PCR, Science, 1993; 259:1749-1754.

(56) McCulloch, R.K., Choong, C.S., Hurley, D.M., An evaluation of competitor type and size for use in the determination of mRNA by Competitive PCR, PCR methods and applications, 1995; 4:219-226.

(57) Zimmermann, K., Mannhalter, W., Technical Aspects of Quantitative Competitive PCR, BioTechniques, 1996; 21:268-279.

(58) Cottrez, F., Aurialult, C., Capron, A., Groux, H., Quantitative PCR: validation of the use of a multispecific internal control, Nucleic Acids Research, 1994; 22:27122713.

(59) Bouaboula, M., Legoux, P., Pességué, B., Delpech, B., Dumont, X, Piechczyk, M., Casellas, P., Shire, D., Standardization of mRNA titration using a polymerase chain reaction method involving co-amplification with a multispecific internal control, J. Biol. Chem., 1992; 267:21830-21838.

(60) García-Cañas, V., González, R., Cifuentes, A., Ultrasensitive detection of genetically modified maize DNA by capillary gel electrophoresis with laser 
induced fluorescence using different fluorescent intercalating dyes, J. Agric. Food Chem., 2002; 50:4497-4502.

(61) Stalbom, B.M., Torvén, A., Lundberg, L.G., Application of capillary electrophoresis to the post-polymerase chain reaction analysis of rat mRNA for gastric $\mathrm{H}^{+}, \mathrm{K}^{+}$-ATPase, Anal. Biochem., 1994; 217:91-97.

(62) Fasco, M.J., Treanor, C.P., Spivak, S., Finge, H.L., Kaminsky, L.S., Quantitative RNA-Polymerase Chain Reaction-DNA analysis by Capillary Electrophoresis and Laser-Induced-Fluorescence, Anal. Biochem., 1995; 224:140-147.

(63) Borson, N.D., Straus-bauch, M.A., Wettstein, P.J., Oda, R.P., Johnston, S.L., Lenders, J.P., Direct quantitation of RNA transcripts by competitive single-tube RT-PCR and capillary electrophoresis, BioTechniques, 1998; 25:130-137.

(64) Lim, E., Tomita, A.V., Thilly, W.G., Polz, M.F., Combination of competitive Quantitative PCR and constant-denaturant capillary electrophoresis for highresolution detection and enumeration of microbial cells, Appl. Environm. Microbiol., 2001; 67: 3897-3903.

(65) Hardegger, M., Brodmann, P., Herrmann, A., Quantitative detection of the 35S promoter and the NOS terminator using quantitative competitive PCR, Eur. Food Res. Technol., 1999; 209:83-87. 
(66) Hupfer, C., Hotzel, H., Sachse, K., Moreano, F., Engel, K.H., PCR-based quantification of genetically modified Bt maize: single-competitive versus dualcompetitive approach, Eur. Food Res. Technol., 2000; 212:95-99.

(67) Wurz, A., Bluth, A., Zeltz, P., Pfeifer, C., Willmund, R., Quantitative analysis of genetically modified organisms (GMO) in processed food by PCR-based methods, Food Control, 1999; 10:385-389.

(68) Freeman, W.M., Walker, S.J., Vrana, K.E., Quantitative RT-PPCR: Pitfalls and potential, BioTechniques, 1999; 26:112-125.

(69) Hall, L.L., Bichnell, G.R., Primrose, L., Pringle, J.H., Shaw, J.A., Furness, P.N., Reproducibility in the quantification of mRNA levels by RT-PCR-ELISA and RT competitive-PCR-ELISA, BioTechniques, 1998; 24:652-657.

(70) Hübner, P.; Studer, E.; Lüthy, J., Quantitation of genetically modified organisms in food, Nature Biotechnology, 1999; 17:1137-1138.

(71) Lockey, C., Otto, E., Long, Z., Real-Time fluorescence detection of a single DNA molecule, BioTechniques, 1998; 24:744-746.

(72) Higuchi, R., Fockler, C., Dollinger, G., Watson, R., Kinetic PCR analysis: RealTime monitoring of DNA amplification reactions, BioTechnology, 1993; 11:10261030. 
(73) Ririe, K.M., Rasmussen, R.P., Wittwer, C.T., Product differentiation by analysis of DNA melting curves during the polymerase chain reaction, Anal. Biochem., 1997; 254:154-160.

(74) Morrison, T.B., Weis, J.J., Wittwer, C.T., Quantification of low-copy transcripts by continuous SYBR Green I monitoring during amplification, BioTechniques, 1998; 24:954-962.

(75) Wittwer, C.T., Herrmann, M.G., Moss, A.A., Rasmussen, R.P., Continuous fluorescence monitoring of rapid cycle DNA amplification, BioTechniques, 1997; 22:130-138.

(76) Holland, P.M., Abramson, R.D., Watson, R., Gelfand, D.H., Detection of specific polymerase chain reaction product by utilizing the 5'-3' exonuclease activity of Thermus aquaticus DNA polymerase, Proc. Natl. Acad. Sci. USA, 1991; 88:72767280.

(77) Whitcombe, D., Theaker, J., Guy, S.P., Brown, T., Little, S., Detection of PCR products using self-probing amplicons and fluorescence, Nature Biotechnol., 1999; 17:804-807.

(78) Täpp, I., Malmberg, L., Rennel, E., Wik, M., Syvänen, A.C., Homogeneous scoring of single-nucleotide polymorphisms: Comparison of the 5'-Nuclease TaqMan assay and molecular beacon probes, BioTechniques, 2000; 28:732-738. 
(79) Tyagi, S., Kramer, F.R., Molecular Beacons: Probes that fluoresce upon hybridization, Nature Biotechnol., 1995; 14:303-308.

(80) Nazarenko, I.A., Bhatnagar, S.K., Hohman, R.J., A closed tube format for amplification and detection of DNA based on energy transfer, Nucleic Acids Research, 1997; 25:2516-2521.

(81) Wolffs, P., Knutsson, R., Sjöback, R., Radstrom, P., PNA-Based light-Up Probes for Real-Time detection of sequence-specific PCR products, BioTechniques, 2001; 31:766-771.

(82) Nazarenko, I., Lowe, B., Darfler, M., Ikonomi, P., Schuster, D., Rashtchian, A., Multiplex quantitative PCR using self-quenched primers labeled with a single fluorophore, Nucleic Acids Research, 2002; 30 No. e37.

(83) Hernández, M., Río, A., Esteve, T., Prat, S., Pla, M., A rapeseed-specific gene, acetyl-CoA carboxylase, can be used as a reference for qualitative and Real-Time quantitative PCR detection of transgenes from mixed food samples, J. Agric. Food Chem., 2001; 49:3622-3627.

(84) Einspanier, R., Quantifying genetically modified material in food: searching for a reliable certification, Eur. Food Res. Technol., 2001; 213:415-416. 
(85) Vaïtilingom, M., Pijnenburg, H., Gendre, F., Brignon, P., Real-Time quantitative PCR detection of genetically modified Maximizer maize and Roundup Ready soybean in some representative foods, J. Agric. Food Chem., 1999; 47:5261-5266.

(86) Terry, C.F., Harris, N., Event-specific detection of Roundup Ready Soja using two different real time PCR detection chemistries, Eur. Food Res. Technol., 2001; 213:425-431.

(87) Holck, A., Va, M., Didierjean, L., Rudi, K., 5’-Nuclease PCR for quantitative event-specific detection of the genetically modified Mon810 MaisGard Maize, Eur. Food Res. Technol., 2002; 214:449-453.

(88) Zeitler, R., Pietsch, K., Waiblinger, H.U., Validation of real-time PCR methods for the quantification of transgenic contamination in rape seed, Eur. Food Res Technol, 2002; 2143:346-351.

(89) Höhne, M., Satisi, C.R., Meyer, R., Real-time multiplex PCR: An accurate method for the detection and quantification of 35-CaMV promoter in genetically modified maize-containing food, Eur. Food Res. Technol., 2002; DOI 10.1007/s00217-0020503-4.

(90) Permigeat, H.R., Reggiardo, M.I., Vallejos, R.H., Detection and quantification of transgenes in grains by multiplex and Real-Time PCR, J. Agric. Food Chem., 2002; 50:4431-4436. 
(91) AGBIOS. 2002. Biotech Crop Database. Ottawa, Canada. www.agbios.com

(92) Henegariu, O., Heerema, N.A., Dlouhy, S.R., Vance, G.H., Vogt, P.H., Multiplex PCR: Critical Parameters and step-by-step protocol, BioTechnology, 1997; 11:1026-1030.

(93) Kapley, A., Lampel, K., Purohit, H.J., Thermocycling steps and optimization of multiplex PCR, Biotechnology letters, 2000; 22:1913-1918.

(94) Shuber, A.P., Grondin, V.J., Klinger, K.W., A simplified procedure for developing multiplex PCRs, Genome Research, 1995; 5:488-493.

(95) Schouten, J.P., McElgunn, C.J, Waaijer, R., Zwijnenburg, D., Diepvens, F., Pals, G., Relative quantification of 40 nucleic acid sequences by multiplex ligationdependent probe amplification, Nucl. Acids Res., 2002, 30:e57.

(96) Isenberg, A.R., McCord, B.R., Koons, B.W., Budowle, B., Allen, R.O., DNA typing of a polymerase chain reaction amplified D1S80/amelogenin multiplex using capillary electrophoresis and a mixed entangled polymer matrix, Electrophoresis, 1996; 17:1505-1511.

(97) Butler, J.M., Ruitberg, C.M., Vallone, P.M., Capillary electrophoresis as a tool for optimization of multiplex PCR reactions, Fresenius J. Anal. Chem., 2001; 369:200-205. 
(98) Anklam, E., Gadani, F., Heinze, P., Pijnenburg, H., Van Den Eede, G., Analytical methods for detection and determination of genetically modified organisms in agricultural crops and plant-derived food products, Eur. Food Res. Technol., 2002; 214: 3-26.

(99) Hübner, P., Waiblinger, K.U., Pietsch, K., Brodmann, P., Validation of PCR methods for quantitation of genetically modified plants in food, J. AOAC Int., 2001; 84: 1855-1863.

(100) Van den Eede, G., Lipp, M., Eyquem, F., Anklam, E., Validation of a double competitive polymerase chain reaction method for the quantification of GMOs in raw materials, EUR 19676 EN, 2000, European Commission Joint Research Centre, Institute for Health and Consumer Protection, Food Products and Consumer Goods Unit, Ispra, Italy. 
Table 1. Transgenic crops that are detected by screening methods based on $P-35 S$ and nos3'.

\begin{tabular}{|c|c|}
\hline Target & Event \\
\hline \multirow{4}{*}{$P-35 S$} & $\begin{array}{l}\text { Event } 176 \text { maize, Bt11 maize, MON802 maize, MON810 } \\
\text { maize, T25 maize }\end{array}$ \\
\hline & FlavSvr Tomato $^{\mathrm{TM}}$, NEMA 282F Tomato \\
\hline & Roundup Ready Soybean ${ }^{\mathrm{TM}}$ \\
\hline & B33-inv Potato \\
\hline \multirow[t]{3}{*}{ nos3' } & Bt11 maize, GA21 maize, MON802 maize \\
\hline & FlavSvr Tomato $^{\mathrm{TM}}$, NEMA 282F Tomato \\
\hline & Roundup Ready Soybean ${ }^{\mathrm{TM}}$ \\
\hline
\end{tabular}


Table 2. Examples of specific detection methods based on junction fragments.

\begin{tabular}{|c|c|c|c|}
\hline Crop & Event & Target sequence & Reference \\
\hline \multirow[t]{7}{*}{ Maize } & Bt176 & P-CDPK - cryIA(b) & $(9,44)$ \\
\hline & & P-PEPC - $c r y I A(b)$ & (30) \\
\hline & Bt11 & adh1-1S IVS6 - cryIA(b) & (30) \\
\hline & $\mathrm{T} 25$ & pat - T-35S & (30) \\
\hline & GA21 & OTP-m-EPSPS & (30) \\
\hline & MON810 & P-35S - hsp70 int. & (8) \\
\hline & & hsp70 int. - cryIA(b) & (30) \\
\hline \multirow[t]{3}{*}{ Soybean } & Roundup Ready ${ }^{\mathrm{TM}}$ & P-35S - CP4 EPSPS & (36) \\
\hline & & & (28) \\
\hline & & CP4 EPSPS - nos3' & (38) \\
\hline Tomato & FLVR-SVR $^{\mathrm{TM}}$ & $\begin{array}{l}\text { P-35S - polygalacturonidase } \\
\text { ansitsense gen }\end{array}$ & (39) \\
\hline Potato & Var. Desiree & P-B33 - gbss antisense gen & (37) \\
\hline
\end{tabular}


FIGURE LEGENDS

Figure 1. Schematic representation of junction and edge fragments in a typical transgenic construction inserted in the genome. Blank: DNA sequences present in the construction without a specific function; $\mathrm{P}_{1}$ and $\mathrm{P}_{2}$ : promoters; $\mathrm{T}_{1}$ and $\mathrm{T}_{2}$ : terminators; TM: gene used as transformation marker; G: gene of interest; I: intron.

Figure 2. Outline of a two-step strategy used for the quantification of the GMO content in food samples by QC-PCR.

Figure 3. Outline of different alternatives employed to induce sequence-specific fluorescence emission in Real-Time PCR. A (TaqMan ${ }^{\mathrm{TM}}$ probes), B (Primers Scorpion $^{\mathrm{TM}}$ ), C (Molecular Beacons ${ }^{\mathrm{TM}}$ ) and D (FRET Technology). 